\title{
FOOD AND THE PERCEPTION OF EATING: THE CASE OF YOUNG TAIWANESE CONSUMERS
}

\author{
Elaine Chiao Ling YANG (Corresponding Author) \\ PhD Student, Griffith University \\ Department of Tourism, Sport \& Hotel Management, \\ Griffith Business School, Griffith University, \\ 170 Kessels Road, Nathan, QLD 4111, Australia \\ Email: elaine.yang@griffithuni.edu.au
} Mobile: +61423571246

\author{
Catheryn KHOO-LATTIMORE \\ Senior Lecturer, Griffith University \\ Department of Tourism, Sport \& Hotel Management, \\ Griffith Business School, Griffith University, \\ 170 Kessels Road, Nathan, QLD 4111, Australia \\ Email: c.khoo-lattimore@griffith.edu.au
}

\section{ACKNOWLEDGEMENT}

This work was supported by Taylor's Research Grant Scheme (TRGS) Program [Project Code: TGRS/2/2011/TCHT/008]. This paper has not been published elsewhere and has not been submitted simultaneously for any other publication. 


\title{
FOOD AND THE PERCEPTION OF EATING: THE CASE OF YOUNG TAIWANESE CONSUMERS
}

\begin{abstract}
This study explores the food perception of young Taiwanese consumers, a growing market segment in the restaurant industry. An innovative qualitative tool known as the Zaltman Metaphor Elicitation Technique (ZMET) was employed to elicit deeper thoughts and emotions of young consumers. Twelve Taiwanese from Generation Y were invited to participate in a ZMET interview where they expressed their perceptions concerning food and eating through self-collected images. The data was analyzed using constant comparative method and charted on a consensus map. Five themes have evolved from the consensus map: health, trying new food, sharing, enhancing knowledge, and happiness. Findings reveal that young Taiwanese consumers are health-conscious and have high acceptance of novel food. They perceive food as a means of enjoyment and fostering social relationships. This study has contributed additional perspectives to existing literature by revealing the function of food in enhancing knowledge, as well as unveiling the deep-seated meanings of food associated with consumer's personal relevance values. Marketing implications for the restaurant industry targeting young Taiwanese consumers are proposed.
\end{abstract}

Keywords: Food Perception, Young Consumers, Restaurant Industry, Taiwan, Qualitative, ZMET 


\section{Introduction}

In the past decade, the tourism exchange between Taiwan and Malaysia has achieved a tremendous growth (Taiwan Tourism Bureau, 2010). In 2010, the number of Malaysian tourists visiting Taiwan has increased by $70 \%$ compared to the previous year. As for Taiwanese tourists visiting Malaysia, the number has increased by 38\%. These figures indicate an optimistic foreign cuisine market in both countries, especially when consumers from both markets share similar food choice motives (Prescott, Young, O'Neill, Yau, \& Stevens, 2002). In fact, the number of Taiwanese gourmet outlets is rising in Malaysia over the past few years. One of the examples is Chatime, a Taiwanese beverage franchise which has established more than 90 outlets in Malaysia in the past four years (Chatime, 2013). This is not the case however, for Malaysian restaurants in Taiwan indicating that Malaysian restaurants are struggling to obtain a stance in Taiwanese exotic food market (Wang \& Shen, 2010). According to Lo's (2005) investigation on 2000 foreign restaurants in Taipei, Japanese restaurants took up the highest percentage, followed by American, Korean, Mexican, French, Italian, and Thailand, while Malaysian restaurants were not even included in the statistics. Wang and Shen (2010) also pointed out that the number of Malaysian restaurants in Taiwan are relatively small compared to other ethnic restaurants. This seems surprising given that even Malaysia's neighboring country, Thailand has succeeded in gaining a foothold in the Taiwanese gastronomy market (Chi \& Jackson, 2011; Wang \& Shen, 2010).

For any business venture to succeed, the consumer factor should be treated with extra circumspection. The industry needs to identify the most appropriate market and understand deeply their consumers' preferences and behavior for the formulation 
of effective marketing strategies. Scholars have cautioned the generational differences in consumer behavior. Consumers from different age groups hold distinctive formative experience within a generation which molds their beliefs, values, preferences, and perceptions (Harrington, Ottenbacher, Staggs, \& Powell, 2012; Paul, 2001). This study intends to focus on young consumers or members of Generation Y who are born between 1977 and 1994 (Kim \& Jang, 2014; Paul, 2001). The marketing potential of young consumers has been widely documented in prior studies (Harrington et al., 2012; Jang, Kim, \& Bonn, 2011; Kueh \& Voon, 2007). Labelled as the next big spending group, Gen Yers who were socialized in a materialistic society have a higher level of disposable income and live a more affluent lifestyle (Farris, Chong, \& Dunning, 2002; Tomkins, 1999). A large portion of the young consumers' spending goes to food and beverage expenditure with the prevalence of eating-out culture (Jang et al., 2011; Kueh \& Voon, 2007). This market segment is particularly significant to Taiwanese food market. Due to the changing lifestyle and disintegration of traditional family structure, $90 \%$ of Taiwanese eat out (Bureau of Foreign Trade Taiwan, 2013) of which young consumers comprise almost a third of the whole population (Taiwan Department of Household Registration Affairs, 2014).

This study aims to explore the food perception of young Taiwanese consumers in order to provide a deeper understanding of the target market. Instead of following traditional exotic food research which focuses on authenticity (Ebster \& Guist, 2004; Muñoz \& Wood, 2009) and identity (Chi \& Jackson, 2011; Wang \& Shen, 2010), this study attempts to return to the most basic question by looking into how young Taiwanese consumers perceive food and eating in order to gain a more holistic understanding of the target market. Given this aim, the paper firstly anchors on the 
experiential consumption framework and contextualizes Taiwanese food and eating within the consumer behavior literature. Within this scope, it considers past studies on meanings and values of food. It asks the question, "What is the meaning of food and eating in the lives and the minds of young Taiwanese consumers?” By doing so, the contributions of this study are twofold. First, it advances the existing food choice model by exploring the underlying antecedents, which is the meanings of food and eating. Second, it provides marketing implications for the restaurant industry targeting on young consumers in Taiwan. This is a pioneer study of young Taiwanese consumers' food perception, focusing on the meanings of food and eating. Having done so, the knowledge adds to existing frameworks on food choice, food preference and eating attitude of young consumers, and Taiwanese food culture.

\section{Literature review}

Food is more than just a sustenance - in fact, Falk (1996) opines that food can mean fuel, poison, medicine, and pleasure. From the literature, the meanings of food and eating can be broadly categorized into two themes: utilitarian and experiential. The utilitarian function of food refers to the physiological need of human, which is to satisfy hunger (Maslow, 1943) while the experiential dimension of food emphasizes the hedonic aspects of eating (Ryu, Han, \& Jang, 2010; Stroebe, Papies, \& Aarts, 2008). The latter points to the symbolic meanings of food and eating, for example, people eat to console (Counihan, 1999), reward (Jones, 2005; Lupton, 1996), and sympathize (Jones, 2005). When viewed in the utilitarian versus experiential continuum, food has progressed from being a source of nutrition and sensory pleasure to a social marker (Counihan, 1999; Neely, Walton, \& Stephens, 2014; Warde \& Martens, 2000), a source and target of metaphor (Korthals, 2008; Rozin, 1996b), a 
moral entity (Rozin, 1996a, 1996b), and a representation of one’s identity (Bisogni, Connors, Devine, \& Sobal, 2002). Indeed, the way consumers perceive food will affect their food choice or at least the intention to consume. This relationship is supported by the renowned Theory of Planned Behavior (TPB), which examines the effect of attitude, subjective norm, and perceived behavioral control on eating intention (Chen, 2007; Conner \& Armitage, 2002; Dennison \& Shepherd, 1995). The TPB however, was criticized for merely being able to predict behavioral intention rather than actual food choice (Conner \& Armitage, 2002). This therefore raises the need to develop a more comprehensive and fitting food choice model grounded within the discipline of food study.

Scholars have indeed attempted to address this need for model development. Furst et al. (1996) for example, conceptualized a model of food choice process which covered the influences of ideals, personal factors, social contexts, food characteristics, and the available resources. The impact of these influencing factors were mediated by value negotiations which measured dimensions such as subjective sensory perceptions, health beliefs, money value, accessibility, relationships with others, and quality of the decision. Building upon the work of Furst et al. (1996), several studies have examined values as the mediators of food choice. Connors, Bisogni, Sobal, and Devine (2001) revealed five food-related values impacting the New Yorkers’ personal food system, namely, taste, health, cost, time, and social relationships while Lusk and Briggeman (2009) compiled a list of 11 food values of which safety, nutrition, taste, and price were found to be the most relevant factors to consumers. Most of the foodrelated values in existing literature are predominantly focussed on the utilitarian dimension, that is, on the attributes of food themselves (e.g. taste, nutrition) or the 
outcomes of food consumption (e.g. health). One of the limited exceptions is Lin and Chen's (2014) recent work on Chinese outbound tourists where three food and food service needs were revealed, namely physiological and safety, self-actualization, and self-esteem. Lin and Chen (2014) focused on the relationship between food needs and travel behaviour instead of exploring the experiential dimension food. This means that there is still much room left for the exploration of the deep-seated symbolic values of food, such as the underlying values of being healthy.

Although not directly focussed on exploring the meanings of food, some studies have inadvertently "uncovered" values attached to the consumption of specific food groups, for example organic food (Zanoli \& Naspetti, 2002), fast food (Park, 2004), and slow food (Paxson, 2005; Pietrykowski, 2004). The number of studies which have attempted to explore meanings of food and consumption have done so from the perspectives of different social segments, including female consumers (Thorsen, 1991), children (Kaplan, 1999), elderly consumers (Crogan, Evans, Severtsen, \& Shultz, 2004; Quandt, Arcury, Bell, McDonald, \& Vitolins, 2001; Wu \& Barker, 2008), and cancer patients (McQuestion, Fitch, \& Howell, 2011), but not yet members of Generation Y. Given the established fact that theories developed for western consumers may not apply to eastern consumers, other scholars have investigated the meanings of food that are specific to cultural occasions or cultural groups. Therefore, we are somewhat advanced in our understanding of how food is consumed in occasions such as Chinese New Year (Fong, 2000; Liu, 2011), for example, the eating of dumplings during Chinese New Year symbolizes farewell to the past and welcome to the future (Liu, 2011). 
The interest of this study is to enhance understanding of the meanings of food to young consumers in Taiwan. While there are studies investigating Chinese interpretation of food (Chang, Kivela, \& Mak, 2010; Lin \& Chen, 2014; Wong, 2010; Wu \& Cheung, 2004; Wu \& Barker, 2008), little attention has been given to the Taiwanese community, not to mention the young consumers segment in Taiwan. Past studies (Chang et al., 2010; Wu \& Cheung, 2004) have documented the intergroup disparity on the meanings of food within the Chinese communities, particularly, the distinction between Chinese (mainland China) and Taiwanese food preference have been recorded. This implies the need to explore the meanings of food for Chinese from different places. On the other hand, scholars have urged for further research on Gen Y consumers in restaurant industry due to the relatively scant attention given into this segment (Kueh \& Voon, 2007). The limited food studies investigating young consumers had worked on various perspectives and contexts, including service quality expectation of young consumers in Malaysia (Kueh \& Voon, 2007); key restaurant attributes affecting young consumers' experiences in United States (Harrington et al., 2012); food practice and social relationships among young people (Neely et al., 2014); attitudes of young Taiwanese towards healthy eating (Sun, 2008). Among the limited literature on young consumers, foodservice attributes received the greatest attention. Food, a mundane and taken-for-granted substance, its meanings remain underexplored within the young consumers segment. One of the few exceptions is Neely et al. (2014) who discussed how young people used food to foster social relationships. Nevertheless, the work of Neely et al. (2014) was a review rather than an empirical study. This study attempts to do so from the perspective of the young Taiwanese consumers, with the aim of drawing insights for both academics and restaurateurs. 
When discussing Taiwanese food culture, the political history of Taiwan should not be overlooked. Taiwanese cuisine is extensively influenced by the island itself, Japan, and southern China, specifically, Guangdong and Fujian provinces (Wu \& Tan, 2001). The multicultural background of Taiwanese food implies that Taiwanese consumers might be more open-minded in accepting exotic food and foreign cuisine, which has been reflected in the proliferation of foreign restaurants in Taipei. According to Lo (2005), 64.12\% of the restaurants in Taipei serve ethnic food from foreign cultures. Young Taiwanese are presumed to have a great degree of acceptance of new food as implied by prior studies (Kueh \& Voon, 2007). In addition to that, the economic transformation in Taiwan has changed the eating habit tremendously. As mentioned, more than $90 \%$ of Taiwanese, especially the younger generation eat out and 34\% of them eat out at least four days a week (Bureau of Foreign Trade Taiwan, 2013). The above figures indicate a potential market for the restaurant industry, including those serving foreign cuisine and those targeting young consumers.

Past studies on Taiwanese food behaviors mainly emphasize on food choice (Chen, 2011b; Prescott et al., 2002; Sun, 2008) and health related research (Chen, 2007, 2008). For instance, Sun (2008) investigated how the health concerns of young Taiwanese affect their food choice. Past studies have also provided evidences on the importance of food safety and cleanliness to Taiwanese consumers (Chen, 2011a; Su, 2012). Most of these studies used a quantitative approach to measure or test relationships (e.g. food choice questionnaire) instead of exploring consumers’ minds. Among these studies, Prescott et al. (2002) compared the food choice motives of consumers in Japan, New Zealand, Taiwan, and Malaysia. Their findings show that 
young Taiwanese (median age range fell between 21 and 30) and Malaysian Chinese consumers are consistent in the four most important food choice factors, which are health, natural content, weight control, and convenience. The authors attributed these similarities to the common cultural value (Chinese value) shared by Taiwanese and Malaysian Chinese. Despite all the aforementioned studies, the existing understanding on Taiwanese consumers is found to be insufficient to provide a holistic explanation for the gloomy status of Malaysian food business in Taiwan. For marketers and practitioners to succeed in Taiwanese food market, it is imperative to first understand the consumers in a deeper sense. With this in mind, the focal point of this study is placed on the meanings and underlying values of food and eating to young Taiwanese, in other words, how the Gen Yers in Taiwan perceive food and eating.

\section{Methodology}

Given the need to delve into a deep understanding of how young Taiwanese eat and perceive food, this study adopted a qualitative approach. According to the epistemology of interpretivism underlying qualitative research, the researcher and the object of study are interactively connected which results in mutually created findings (Guba \& Lincoln, 1994). Thus, the researcher's experiences, beliefs, and values are incorporated into the research design and data analysis. In this study, all researchers are Malaysian Chinese but more importantly, the primary interviewer has lived in Taiwan for five years and has observed first hand, the food and eating culture in Taiwan - this researcher's values are greatly influenced by both cultures. Therefore, the researcher is able to consider the cultural differences between both countries and make appropriate adjustment when conducting the research and interpreting the findings. 
This research employs ZMET to explore young Taiwanese food and eating perception. Unlike the traditional structured interview, ZMET helps the researcher and respondents think out of the box as no interview questions or answers can be prepared, at least not until the respondents present the photos they collected. Using respondents' self-collected photographs in in-depth interviews, the results from ZMET are deemed to be more dependable and pertinent when compared to conventional interviews (Chen, 2006; Christensen \& Olson, 2002; Khoo-Lattimore, 2008; Khoo-Lattimore \& Prideaux, 2013; Warden \& Chen, 2009). The main reason is that human thought occurs as image (Humphrey, 1999; Zaltman, 1997) and 80\% of human communication is nonverbal (Pinker, 2007). Word is only a tool for the individual to communicate his/her pictorial thought to other people (Zaltman, 1997). In addition, many of the thoughts stay below the conscious level. Such hidden knowledge is valuable and yet difficult to access. Zaltman (1997) pointed out that this hidden knowledge can be elicited through metaphors, specifically visual metaphors. Therefore, it is reasonable to assume that by using respondents' self-prepared photographs, more relevant information, both spoken and tacit, can be elicited. Thus, building upon the theory of photo-elicitation, ZMET distinguishes itself from traditional structured and semi-structured interviews (Zaltman \& Coulter, 1995). The laddering technique from means-end chain theory (Gutman, 1982) is employed throughout the ZMET interview to probe for deeper meaning of the visual metaphor. Laddering is one of the most established in-depth interview techniques which is particularly effective in surfacing consumer's personal values on a product attribute (Christensen \& Olson, 2002). Through laddering, the interviewer is able to peel off the respondents' mental model layer by layer, from the functional benefit of a 
product/service to the consequence of consumption, and eventually reach the personal relevance or ultimate value attached to that particular attribute.

According to Zaltman (1997), generally four or five respondents are enough to generate all the constructs on the consensus map. At the point of saturation (Patton, 2002), 12 Taiwanese who grew up and currently reside in Taiwan participated in this research (Table 1). The sample was selected using a combination of purposeful sampling methods to ensure triangulation and flexibility to meet multiple interests and needs (Patton, 2002). To be specific, three sampling strategies were employed, including criterion sampling, snowball sampling, and convenience sampling. The sample size was referred to past ZMET studies which generally included between eight and sixteen respondents (Chen, 2006; Christensen \& Olson, 2002; KhooLattimore, 2008; Khoo-Lattimore, Thyne, \& Robertson, 2009; Warden \& Chen, 2009; Yang, Khoo-Lattimore, \& Lai, 2013). The respondents were instructed to collect six to eight photographs that can best represent their thoughts and feelings on food and eating. These photographs are the metaphors which contain both evident and hidden meanings. A 90-minute in-depth interview was conducted face-to-face with each of the respondents in Taiwan. The 9-steps ZMET procedure was adopted from Zaltman and Coulter (1995). The complete manual of ZMET was not available due to patent license restriction which has expired in March 2013. Although it was a patented tool, academics were allowed to use ZMET for academic purpose without violating the patent rights (Khoo-Lattimore \& Prideaux, 2013).

[Insert Table 1 here] 
All the interviews were recorded and transcribed verbatim. Content coding of the 233 pages of transcripts were all done manually instead of using any qualitative research software. As Khoo-Lattimore (2008) pointed out, qualitative research software could be too rigid in the abstraction of constructs and eventually distant the researcher and the data. Indeed, analysis software programs which largely emphasize on quantity rather than meanings might trivialize the content of the text (Krippendorff, 2004). Undeniably, these software programs would make the analysis process more efficient. However, they remain a tool to organize and store codes instead of doing intellectual analysis and the researcher still plays an active role in coding and extracting (Lichtman, 2013). Therefore, qualitative analysis software does not warrant objectivity (Ryan, 2009). Rather, subjectivity and interpretive research are inseparable as the underlying philosophical stance of interpretivism assumes a subjectivist epistemology which acknowledges the role of researcher as an instrument to elicit meanings (Denzin \& Lincoln, 2013). While acknowledging the value-laden nature of qualitative research, trustworthiness and rigor of this study are achieved through the steps outlined in Zaltman and Coulter (1995): Engaging respondents in a personal, indepth interview; triangulating across methods in the multiple steps used in ZMET; interacting with the respondents to discuss the constructs elicited; triangulating across the researchers; and having respondents to cross check the elicited constructs.

Constant comparative analysis derived from grounded theory (Glaser \& Strauss, 1967) was adopted as the guideline for data coding and analysis. In order to ensure the inter-rated reliability, the analysis was completed by one of the authors who has lived in Taiwan for more than five years. As this study is exploratory in nature, open coding was employed. The coding was cross checked and triangulated by 
the other researcher. The transcripts were reviewed and examined carefully to surface 60 constructs. A complicated consensus map was illustrated based on the constructs and the relationships among the constructs. The resulting map was complex with hundreds of construct boxes and linkages. In order to develop an interpretable and meaningful consensus map, only constructs agreed by at least half of the respondents were considered for further analysis (Zaltman, 1997). The data were scrutinized further for construct pairs. A construct pair is a pair of constructs that linked to each other through the respondents' reasoning process. For any construct pair to be retained in the consensus map, it has to be agreed by at least one-third of the respondents (Zaltman, 1997). However, other researchers suggest that there is no standard cut off level or consensus level for the consensus map as it all depends on the research questions and objectives (Christensen \& Olson, 2002).

\section{Findings and discussions}

Figure 1 presents the consensus map of young Taiwanese food and eating perception in broad meaning themes. The consensus map depicts the main ideas identified by respondents when they thought of food and eating. Connected constructs were grouped together in different thematic region. Five themes (trying new food, health, sharing, enhancing knowledge, and happiness) were revealed. Different shapes were used to identify the themes, for example, ideas related to sharing were enclosed by rectangular boxes while constructs attached to happiness were illustrated in round boxes. The themes were determined by the dominant construct in each thematic region. A dominant construct received the highest level of consensus (n). It was either the most common originating point ( $x$; number to the left of the hyphen) or destination point (y; number to the right of the hyphen) in the reasoning process. For 
instance, there were five closely interrelated constructs grouped under the thematic region of Sharing. The theme was identified by comparing the value of $\mathrm{n}, \mathrm{x}$, and $\mathrm{y}$ for each construct. Although Sharing, People, and Warm Relationship with Others received an identical consensus level $(n=11)$, the theme was named under Sharing because it had the highest value of $\mathrm{x}(\mathrm{x}=10)$. It indicated that 10 ideas were originated from Sharing. Nevertheless, Figure 1 only recorded 2 out of the 10 linkages due to the selected cut-off value as discussed in the previous section.

[Insert Figure 1 here]

\section{Theme 1: Health}

One of the most prominent findings is that of young Taiwanese being concerned with health when it comes to food and eating. Three constructs have evolved around the theme of health, namely, health, freedom, and happiness. A wide variety of images were used by the respondents to express their concerns for health, for instance, a fairy, a temple, and a diagram of the body structure. As illustrated in Figure 2, one would simply agree that the first two images have no direct implications on health at all. However, the ZMET interview technique surfaced much deeper. The image of a fairy was contributed by respondent T2. According to her, the fairy looked very light. She then elaborated that she preferred "natural food with no burden (additive)", because she believed that food with additive was harmful to her health. When referring to the second image of a temple taken in Vietnam, T3 expressed, “eating is a belief”. When asked about her own belief, she stated that eating nutritious food such as vegetables and fruits would give her a healthy body. 
[Insert Figure 2 here]

While respondent T3 perceived food as medicine because eating nutritious food would protect her from illness, respondent T4 had a different point of view. For T4, food is poison: "A lot of food also has negative impacts and with this in mind, food is also a type of poison. There is a lot of research that says eating a certain food can prevent cancer but later there will be another research saying eating too much of that food will have side effects... Who knows if healthy food really means that you will be healthy if you eat it?” His statement corresponds with the concept of gastroanomie suggested by Fischler (1979) - people are confused and do not follow the norms of eating anymore because they are inundated by too much information and many will be overthrown by new findings from time to time.

According to the respondents, the state of their physical and/or psychological wellbeing will affect their freedom, be it freedom in movement or freedom in food choice. T9 stated: "When you are sick, you are restricted to eat this and that... You cannot do whatever you want. Then there is no freedom anymore”. T12 agreed by saying “if you do not have health, you will not have freedom”. When probed further on the importance of freedom, one third of the respondents stated that freedom brought them happiness. To sum up, health leads to freedom and for these young Taiwanese, the ultimate value of freedom is to be happy. Some of the findings are to a certain extent in line with Falk’s (1996) study which suggested the four dimensions of food being medicine, poison, fuel, and pleasure. However, our findings also extend that of Falk's by revealing the consequences and personal relevance values of food being poison or medicine. 


\section{Theme 2: Trying New Food}

This theme reveals the food neophilia tendency of young Taiwanese. There were 11 constructs clustered under this theme. Examples of images (horse riding, colorful lights, and woman in exotic costume) depicting the notion and emotion of trying new food are presented in Figure 3.

\section{[Insert Figure 3 here]}

Upon closer examination of the trying new food construct in Figure 1, we found one construct leading to it while four other constructs emitting from it. The construct that leads to trying new food indicates the factor which attracts young Taiwanese to try new and exotic food, which in this case, is presentation. The image of colorful lights in Figure 3 represents the presentation of a dish. Respondent T5, the photographer of this image declared that presentation is about “...the color. I think the food presentation will affect my appetite and my willingness to try it”. His idea was echoed by many of the respondents. For example, T1 mentioned that "good food... should have colors to attract people. Only when you have colorful food, you will have good appetite. How can you be attracted by a plate of black things? You are unlikely to think that this is going to be something delicious”. The above statement indicates the importance of food presentation for these Taiwanese respondents. A wellpresented food will increase one's appetite and hence, encourage one to try it out. On the other hand, the presentation of food also shapes one's expectations. As illustrated in the consensus map, the outcome of these expectations is either satisfaction or disappointment, both of which will affect the emotion of the respondents. 
Moving the focus back to the center of the theme, four constructs emitting from the theme imply four benefits derived from trying new food. On the emotional aspect, respondents felt happy and excited when they tried something novel. The first image in Figure 3 depicts the emotion of respondent T9 when eating new or exotic food. She said, "Before I rode this horse, I was looking forward to it. It was only when I rode it that I knew it was so exciting. Just like when you try new food, it is very exciting. You do not know what taste you are going to eat. Maybe you will like it or maybe not. You'll never know”. Another respondent (T7) used bungee jump as a metaphor to describe the excitement she had when trying new food: "It is a way of rebelling. Bungee jumpers feel excited when they are about to jump off. I find this kind of excitement in trying new food”. On the functional aspect, the respondents acknowledged that they had gained valuable life experience and new knowledge through trying novel food: "So that I can enrich my life experience. I can know more than other people... It (trying new food) will broaden my horizon” (T1).

In summary, the above findings suggest that food presentation is the factor that attracts these young Taiwanese to try out novel and exotic food. The benefits of trying new food are divided into two dimensions - experiential (happiness, excitement) and functional (enhancing knowledge, life experience). We have assumed earlier that young Taiwanese are open-minded in accepting foreign cuisine as Taiwanese food culture is multicultural in nature. The findings hereby confirm the preceding assumption. 


\section{Theme 3: Sharing}

Seven constructs located on the left of Figure 1 depict the theme of sharing. Images of people were extensively employed by respondents to express their ideas on sharing. Figure 4 presents some of the images collected by the respondents regarding this topic.

\section{[Insert Figure 4 here]}

The first image - two worms sharing a leaf in Figure 4 was collected by respondent T7. The idea of this image is straightforward - sharing. According to T7, sharing was her way to express her care for others: “They (the worms) are sharing. I am willing to share with people that I care for. To me, eating is important. Food is important to worms too. They will die if they do not eat... I hope that I can share things that are important to me with them (people that I care for). It is my way of treating them well."

It is important to clarify that the idea of sharing here is not restricted to tangible substance (i.e. food), but also includes sharing of the intangibles (i.e. feelings, ideas, and knowledge), mainly through conversation. The last image in Figure 5 depicts the idea of sharing during festive season or celebration where people, be it friends or family members get to together and catch up with each other. Echoed with Neely et al. (2014), many respondents agreed that food is an effective lubricant in social function as it generates topics for conversations. It promotes a relaxing atmosphere that encourages people to eat, chat, and share. Respondent T8 stated: "For example, we are talking and there is no food on the table. So you ask and I respond. I 
will feel that there is something being left out. If there is food, we might be able to discuss food. Food can be a topic of conversation”. When the respondents were probed on the importance of sharing, the ultimate value of fostering warm relationship with others was unearthed. The findings seem to demonstrate how young Taiwanese connect food with people and culture. Eating together and celebration symbolize togetherness of the family, merriment, and excitement in the Chinese society. Warden and Chen (2009) studied the traditional Chinese value of 'renao' which literally means hot and noisy. They found that Taiwanese generally associate the seemingly negative crowded and bustling (renao) environment to food and eating. The contribution of the findings here is the revelation of the underlying value of renao, which is to foster warm relationship with others.

\section{Theme 4: Enhancing Knowledge}

Another theme young Taiwanese consumers associate with food and eating is knowledge enhancement. Three constructs located at the bottom of Figure 1 depict the idea of enhancing knowledge through eating. Unlike the other three themes presented earlier, there was not any image prepared by the respondents telling the story of enhancing knowledge as it was actually an outcome of the laddering process. As mentioned previously in Theme 2, respondents revealed that they gained new knowledge and life experience through trying new food. According to these respondents, they would share the knowledge and novel experience they gained from food with their friends and family. At the same time, when they were exchanging these ideas with people, they gained new knowledge: "The fastest method to learn about a place or a country is through food. You are able to try Japanese cuisine without travelling to Japan... It can be a conversation topic... You can exchange 
experience and opinion. It is an emotional exchange. When we are chatting, I can gain things that I do not know from you and vice versa” (T8).

According to the respondents, the knowledge they have gained through food and eating can sometimes be an inspiration. One respondent admitted that knowing more about people from different cultures would change the way she interacted with people (T12). Another respondent mentioned that some knowledge was inspiring to the extent of motivating her to face the difficulties in her life (T1). To conclude, trying new food enhances one's knowledge, which eventually becomes a topic of conversation. And through sharing, one gains new knowledge.

\section{Theme 5: Happiness}

Interestingly, the findings in this study show that three out of the five broad meaning themes are directed to happiness. As presented in Figure 5, images of smiling faces were commonly collected by respondents to express happiness.

\section{[Insert Figure 5 here]}

The image of a bear with a colorful scarf was brought into the interview by respondent T11. She stated: "Life is a very difficult journey just like a black and white picture. But color is added to our life through eating and enjoying good food... The happiness of it (eating) is something unbeatable”. Seven respondents agreed that eating was an enjoyment and almost half of the respondents mentioned that eating delicious food made them feel happy, which meant taste led to happiness. Some of the respondents also suggested that the experience of having delicious food or enjoying a 
particular taste would evoke their past memories: "When you eat something delicious, you will think of happy memories” (T1); “Just like eating white bread in the evening, it will relate back to my childhood memory when I was together with my granny and grandpa” (T2).

All of the respondents brought up the feeling of happiness when they thought of food and eating. The most common conclusion they made was "eating is a happy thing”. And according to respondent T1, the feeling of happiness was like "flying up to the sky”. Scholars have revealed the pleasure dimension of food in the West. The findings here suggest that in an Asian culture such as Taiwan, young people also perceive food as a means of hedonic pursuit.

\section{Implications}

By using ZMET, this paper has contributed a deeper understanding of young Taiwanese food and eating perception. The contribution of ZMET is the richness of the elicited data supported by thick descriptions and meaningful images. Using respondents' self-prepared images, we disclosed the veil behind what young Taiwanese consumers think and feel about food and eating layer by layer, from attributes down to personal relevance values. This contrasts traditional empirical studies using semi-structured interviews or quantitative approaches which normally stop at the stage of consequence due to limitations of the tools. ZMET has allowed the researchers to elicit both spoken and tacit thoughts of the respondents. This is particularly important in some cultures where people are reluctant to discuss their feelings, especially in Middle and Far East (Malhotra, Agarwal, \& Peterson, 1996). Therefore, with the systematic ZMET steps and the assistance of images, Taiwanese 
respondents who fit into the introvert Far East cultural group are encouraged to reveal their thoughts and feelings. Through further laddering and reasoning process, we are able to interpret the deep-seated meanings of food for young Taiwanese consumers in a way that neither quantitative nor conventional qualitative tools can ever deliver.

It is important to acknowledge that the findings of this study are meant to enhance understanding of young consumers in Taiwan from their viewpoint and not designed to be generalized to the whole population. The findings indicate that young Taiwanese respondents are highly concerned with health. Past studies have addressed the importance of health to young Taiwanese consumers (Prescott et al., 2002; Sun, 2008), but this study expands prior studies by revealing the values associated to being healthy, which are freedom and happiness. Findings suggest that Taiwanese respondents have high interest in novel and foreign cuisine. It confirms the premise made earlier based on Lo’s (2005) statistics of Taiwanese foreign food market that Taiwanese are more open-minded in trying new food due to the multicultural background of Taiwanese cuisine and also, young consumers are more adventurous in trying new food (Kueh \& Voon, 2007). It implies positive relationships between (i) the diversity of cultural background and food acceptance level; (ii) age and food acceptance level. Nevertheless, the statement is still far from being conclusive. Further study should be taken to test the evolved relationships.

The findings confirm the pleasure and experiential dimensions of food and consumption. Food and eating are commonly perceived as an enjoyment by the respondents. It implies that food is more than sustenance. Although the function of food being a symbolic pursuit has been widely discussed in the Western literature 
(Jones, 2005; Rozin, 1996a), our findings extend the notion of food as an enjoyment to an Asian context. Furthermore, the respondents also agreed on the function of food being a communication and socializing tool, which resonates with the findings of prior research (Neely et al., 2014; Niva, 2008). Past study (Warden \& Chen, 2009) suggested that Chinese generally associate bustling and crowd to positive food and eating experience. In this paper, we have extended Warden and Chen’s (2009) model by revealing the underlying values of sharing or group dining, which is to foster warm relationships with others. This finding has added to the current literature by suggesting a new functional benefit of food. Through sharing when dining with others, the utilitarian benefit of enhancing one's knowledge is uncovered.

Responding to the emerged findings, a few strategies can be proposed to marketers and practitioners for a better opportunity in Taiwanese food market, targeting young consumers which is a key segment for the restaurant industry. For instance, Malaysian food marketers may try to advertise on the health benefit of ' $B a k$ Kut Teh', a Malaysian herbal soup that is traditionally believed to be good for health and for recovering body strength in order to attract young Taiwanese consumers who are health-conscious. In view of the socializing value of food and eating for Taiwanese respondents, promoting group dining ambience, such as creating a dining space that welcome group diners and friends get together; or providing menus that serve food in communal plates can be some of the effective strategies to capture the foreign cuisine market in Taiwan. Similarly, as the findings have surfaced the pleasure value of food for these respondents, restaurant owners and managers might consider putting more efforts and resources in creating a fun dining experience for the 
young consumers. The core idea is to reinforce happy elements in the dining experience to strengthen the enjoyment aura of food and eating.

The literature suggests that Taiwanese food culture was influenced greatly by the southeast coast of China. This was similar to the case of Malaysian Chinese cuisine as the majority of Malaysian Chinese are the descendants of immigrants from Fujian and Guangdong (Ma, 2003). Perhaps one of the reasons for the failure of Malaysian food business in Taiwan is that Malaysian Chinese food is similar to Taiwanese cuisine to a certain extent. Based on our observation, a number of Malaysian restaurants in Taipei serve Malaysian Chinese food, such as chicken rice and herbal soup (Bak Kut Teh). Although the cooking style and flavor of Malaysian Chinese cuisine and that of Taiwanese are not exactly the same due to assimilation with local culture and geographical distant which result in different cooking ingredients and spices used, Malaysian Chinese cuisine is however, not as exotic as Thai, Japanese or Mexican food. Thus, it is unlikely to capture the eyes of young Taiwanese consumers who perceive food and eating as a means to enhance knowledge and to gain novel experience. Furthermore, Malaysian cuisine is often associated and confused with Singaporean cuisine which also made up of Chinese, Malay, and Indian elements. With the relatively successful tourism promotion in Singapore, the identity of Malaysian cuisine is overshadowed by Singaporean. In order to succeed in the Taiwanese food market, Malaysian food marketers must rethink the unique characteristic and authenticity of Malaysian cuisine and promote them strategically to young Taiwanese consumers who are curious and thirsty for knowledge. 


\section{Conclusion}

Due to time and cost constraint, sampling is the most evident limitation in this study. Admittedly, the time consuming photo collection procedure of ZMET was a setback in the recruitment process. As a consequence, most of the respondents come from similar backgrounds and hold similar lifestyles which might eventually reveal similar perceptions. It might lead to a certain degree of bias. Future research may consider other methods of recruitment. As majority of the respondents in this study are females, future research may explore the role of gender in shaping consumers' food perception or conduct a comparison study to identify if there is any gender difference in the meanings of food. On the methodological aspect, ZMET is a very complicated tool to master. In addition, it is important to acknowledge the existence of subjectivity in the coding and interpretation process due to the inherent value-laden nature of qualitative research. Nevertheless, we have tried to enhance the trustworthiness and rigor of the study by cross-checking the elicited constructs with the respondents. Besides, all the elicited constructs and consensus map were triangulated and audited across the authors.

This study has achieved its objectives in advancing our understanding of what eating means to young Taiwanese and how they perceive food. By using ZMET, the study has successfully revealed some of the deep-seated meanings and values of food for young consumers in Taiwan. The findings of this study have provided a reference for effective strategy planning to food marketers and management practitioners who intend to introduce foreign cuisine to Taiwanese food market, targeting young consumers, the ever-growing segment of the restaurant industry. As the initial quest of this study is inspired by the relatively slow development of Malaysian cuisine in 
Taiwan, future research may consider investigating what young Taiwanese think and feel specifically about Malaysian cuisine in order to find out the underlying reasons of the unpopularity of Malaysian cuisine in Taiwan.

\section{References}

Bisogni, C. A., Connors, M., Devine, C. M., \& Sobal, J. (2002). Who we are and how we eat: A qualitative study of identities in food choice. Journal of Nutrition Education \& Behavior, 34(3), 128-139.

Bureau of Foreign Trade Taiwan. (2013, May 20, 2013). Eating-out culture in Taiwan catering industry’s driving force behind the scenes. Retrieved August 1, 2014, from http://www.taiwanhoreca.com.tw/en_US/industry/news/info.html?id= 8ED0D99AD4A7FC2A

Chang, R. C. Y., Kivela, J., \& Mak, A. H. N. (2010). Food preferences of Chinese tourists. Annals of Tourism Research, 37(4), 989-1011. doi: http://dx.doi.org/10.1016/j.annals.2010.03.007

Chatime. (2013). About Chatime. Retrieved March 31, 2014, from http://www. chatime.com.my/about-chatime

Chen, M.-F. (2007). Consumer attitudes and purchase intentions in relation to organic foods in Taiwan: Moderating effects of food-related personality traits. Food Quality and Preference, 18(7), 1008-1021. doi: http://dx.doi.org/10.1016/j. foodqual.2007.04.004

Chen, M.-F. (2008). Attitude toward organic foods among Taiwanese as related to health consciousness, environmental attitudes, and the mediating effects of a healthy lifestyle. British Food Journal, 111(2), 165-178. doi: $10.1108 / 00070700910931986$ 
Chen, M.-F. (2011a). Consumer's trust-in-food-safety typology in Taiwan: Foodrelated lifestyle matters. Health, Risk \& Society, 13(6), 503-526. doi: $10.1080 / 13698575.2011 .615825$

Chen, M.-F. (2011b). The gender gap in food choice motives as determinants of consumers' attitudes toward GM foods in Taiwan. British Food Journal, 113(6), 697-709. doi: 10.1108/00070701111140052

Chen, P. J. (2006). Sport tourists' loyalty: a conceptual model. Journal of Sport and Tourism, 11(3-4), 201-237. doi: 10.1080/14775080701400620

Chi, H.-C., \& Jackson, P. (2011). Thai food in Taiwan: Tracing the contours of transnational taste. New Formations, 74, 65-81.

Christensen, G. L., \& Olson, J. C. (2002). Mapping consumers' mental models with ZMET. Psychology \& Marketing, 19(6), 477-501. doi: 10.1002/mar.10021

Conner, M., \& Armitage, C. J. (2002). The Social Psychology of Food. Buckingham \& Philadelphia: Open University Press.

Connors, M., Bisogni, C. A., Sobal, J., \& Devine, C. M. (2001). Managing values in personal food systems. Appetite, 36(3), 189-200. doi: http://dx.doi.org/10.1006/appe.2001.0400

Counihan, C. (1999). The anthropology of food and body: Gender, meaning, and power. New York: Routledge.

Crogan, N. L., Evans, B., Severtsen, B., \& Shultz, J. A. (2004). Improving nursing home food service: Uncovering the meaning of food through residents' stories. J Gerontol Nurs, 30(2), 29-36.

Dennison, C. M., \& Shepherd, R. (1995). Adolescent food choice: An application of the Theory of Planned Behaviour. Journal of Human Nutrition and Dietetics, 8(1), 9-23. doi: 10.1111/j.1365-277X.1995.tb00292.x 
Denzin, N. K., \& Lincoln, Y. S. (2013). The landscape of qualitative research. Thousand Oaks, California: SAGE Publications.

Ebster, C., \& Guist, I. (2004). The role of authenticity in ethnic theme restaurants. Journal of Foodservice Business Research, 7(2), 41-52.

Falk, P. (1996). Expelling future threats: Some observations on the magical world of vitamins. In S. Edgell, K. Hetherington \& A. Warde (Eds.), Consumption matters: The production and experience of consumption (pp. 183-203). Oxford: Blackwell.

Farris, R., Chong, F., \& Dunning, D. (2002). Generation Y: Purchasing power and implications for marketing. Academy of Marketing Studies Journal, 6(2), 89101.

Fischler, C. (1979). Gastro-nomie et gastro-anomie. Sagesse du corps et crise bioculturelle de l'alimentation moderne. Communications, 31(4), 189-210.

Fong, M. (2000). 'Luck Talk' in celebrating the Chinese New Year. Journal of Pragmatics, 32(2), 219-237. doi: http://dx.doi.org/10.1016/S0378$\underline{2166(99) 00048-X}$

Furst, T., Connors, M., Bisogni, C. A., Sobal, J., \& Falk, L. W. (1996). Food choice: A conceptual model of the process. Appetite, 26(3), 247-266. doi: http://dx.doi.org/10.1006/appe.1996.0019

Glaser, B. G., \& Strauss, A. L. (1967). The discovery of grounded theory: Strategies for qualitative research. Chicago, IL: Aldine.

Guba, E. G., \& Lincoln, Y. S. (1994). Competing paradigms in qualitative research. In N. K. Denzin \& Y. S. Lincoln (Eds.), Handbook of qualitative research (pp. 105-117). Thousand Oaks: Sage. 
Gutman, J. (1982). A means-end chain model based on consumer categorization processes. Journal of Marketing, 46(2), 60-72.

Harrington, R. J., Ottenbacher, M. C., Staggs, A., \& Powell, F. A. (2012). Generation Y consumers: Key restaurant attributes affecting positive and negative experiences. Journal of Hospitality \& Tourism Research, 36(4), 431-449. doi: $10.1177 / 1096348011400744$

Humphrey, N. (1999). A history of the mind: Evolution and the birth of consciousness. New York, NY: Springer-Verlag.

Jang, Y. J., Kim, W. G., \& Bonn, M. A. (2011). Generation Y consumers' selection attributes and behavioral intentions concerning green restaurants. International Journal of Hospitality Management, 30(4), 803-811. doi: 10.1016/j.ijhm.2010.12.012

Jones, M. O. (2005). Food choice, symbolism, and identity: Bread and butter issues for folkloristics and nutrition studies (American Folklore Society presidential address, October 2005). Journal of American Folklore, 120(476), 129-177. doi: 10.1353/jaf.2007.0037

Kaplan, E. (1999). The meaning of food to kids in working families (Working Paper No. 5), Centre for Working Families. Berkeley, CA: University of California.

Khoo-Lattimore, C. (2008). Home truths: Understanding the key motives that underlie consumer home choice (Unpublished doctoral dissertation). University of Otago, Dunedin, New Zealand.

Khoo-Lattimore, C., \& Prideaux, B. (2013). ZMET: A psychological approach to understanding unsustainable tourism mobility. Journal of Sustainable Tourism, 1-13. doi: 10.1080/09669582.2013.815765 
Khoo-Lattimore, C., Thyne, M., \& Robertson, K. (2009). The ZMET method: Using projective technique to understand consumer home choice. The Marketing Review, 9(2), 139-154. doi: 10.1362/146934709X442674

Kim, D., \& Jang, S. (2014). Motivational drivers for status consumption: A study of Generation Y consumers. International Journal of Hospitality Management, 38(0), 39-47. doi: http://dx.doi.org/10.1016/j.ijhm.2013.12.003

Korthals, M. (2008). Food as a source and target of metaphors: Inclusion and exclusion of foodstuffs and persons through metaphors. Configurations, 16(1), 77-92.

Krippendorff, K. (2004). Content analysis:An introduction to its methodology (2nd ed.). Thousand Oaks: Sage.

Kueh, K., \& Voon, B. H. (2007). Culture and service quality expectations: Evidence from Generation Y consumers in Malaysia. Managing Service Quality, 17(6), 656-680. doi: 10.1108/09604520710834993

Lichtman, M. (2013). Qualitative research in education: A user's guide (3rd ed.). Thousand Oaks, CA: Sage.

Lin, Y.-C., \& Chen, C.-C. (2014). Needs assessment for food and food services and behavioral intention of Chinese group tourists who visited Taiwan. Asia Pacific Journal of Tourism Research, 19(1), 1-16. doi: $10.1080 / 10941665.2012 .724017$

Liu, J. (2011). Chinese food. Cambridge: Cambridge University Press.

Lo, T.-C. (2005). The operation of exotic restaurants to consumers' perception and purchase intentions (Unpublished master's thesis). Shih Hsin University, Taipei.

Lupton, D. (1996). Food, The body and the self. London: Sage. 
Lusk, J. L., \& Briggeman, B. C. (2009). Food values. American Journal of Agricultural Economics, 91(1), 184-196. doi: 10.1111/j.14678276.2008.01175.x

Ma, L. J. C. (2003). Space, place, and transnationalism in the Chinese diaspora. In L. J. C. Ma \& C. L. Cartier (Eds.), The Chinese diaspora: Space, place, mobility, and identity (pp. 1-50). Maryland, MD: Rowman \& Littlefield.

Malhotra, N. K., Agarwal, J., \& Peterson, M. (1996). Methodological issues in crosscultural marketing research - A state-of-the-art review. International Marketing Review, 13(5), 7-43.

Maslow, A. H. (1943). A theory of human motivation. Psychological Review, 50(4), 370-396.

McQuestion, M., Fitch, M., \& Howell, D. (2011). The changed meaning of food: Physical, social and emotional loss for patients having received radiation treatment for head and neck cancer. European Journal of Oncology Nursing, 15(2), 145-151. doi: http://dx.doi.org/10.1016/j.ejon.2010.07.006

Muñoz, C. T., \& Wood, N. T. (2009). A recipe for success: Understanding regional perceptions of authenticity in themed restaurants. International Journal of Culture, Tourism and Hospitality Research, 3(3), 269-279.

Neely, E., Walton, M., \& Stephens, C. (2014). Young people's food practices and social relationships. A thematic synthesis. Appetite, 82(1), 50-60. doi: 10.1016/j.appet.2014.07.005

Niva, M. (2008). Consumers and the conceptual and practical appropriation of functional food (Unpublished doctoral dissertation). University of Helsinki, Finland. 
Park, C. (2004). Efficient or enjoyable? Consumer values of eating-out and fast food restaurant consumption in Korea. International Journal of Hospitality Management, 23(1), 87-94. doi: http://dx.doi.org/10.1016/j.ijhm.2003.08.001

Patton, M. Q. (2002). Qualitative research and evaluation methods (3rd ed.). Thousand Oaks, CA: Sage.

Paul, P. (2001). Getting inside Gen Y. American Demographics, 23(9), 42-49.

Paxson, H. (2005). Slow food in a fat society: Satisfying ethical appetites. gastronomica: The Journal of Food and Culture, 5(1), 14-18. doi: 10.1525/gfc.2005.5.1.14

Pietrykowski, B. (2004). You are what you eat: The social economy of the slow food movement. Review of Social Economy, 62(3), 307-321. doi: $10.1080 / 0034676042000253927$

Pinker, S. (2007). The language instinct: How the mind creates language. New York, NY: HarperCollins.

Prescott, J., Young, O., O'Neill, L., Yau, N. J. N., \& Stevens, R. (2002). Motives for food choice: A comparison of consumers from Japan, Taiwan, Malaysia and New Zealand. Food Quality and Preference, 13(7-8), 489-495. doi: 10.1016/S0950-3293(02)00010-1

Quandt, S. A., Arcury, T. A., Bell, R. A., McDonald, J., \& Vitolins, M. Z. (2001). The social and nutritional meaning of food sharing among older rural adults. Journal of Aging Studies, 15(2), 145-162. doi: http://dx.doi.org/10.1016/S0890-4065(00)00023-2

Rozin, P. (1996a). The socio-cultural context of eating and food choice. In H. L. Meiselman \& H. J. H. MacFie (Eds.), Food choice, acceptance and consumption (pp. 83-104). London: Blackie. 
Rozin, P. (1996b). Towards a psychology of food and eating: From motivation to module to model to marker, morality, meaning, and metaphor. Current Directions in Psychological Science, 5(1), 18-24. doi: 10.2307/20182380

Ryan, M. (2009). Making visible the coding process: Using qualitative data software in a post-structural study. Issues in Educational Research, 19(2), 142-161.

Ryu, K., Han, H., \& Jang, S. (2010). Relationships among hedonic and utilitarian values, satisfaction and behavioral intentions in the fast-casual restaurant industry. International Journal of Contemporary Hospitality Management, 22(3), 416-432. doi: 10.1108/09596111011035981

Stroebe, W., Papies, E. K., \& Aarts, H. (2008). From homeostatic to hedonic theories of eating: Self-regulatory failure in food-rich environments. Applied Psychology, 57, 172-193. doi: 10.1111/j.1464-0597.2008.00360.x

Su, C.-S. (2012). An importance-performance analysis of dining attributes: A comparison of individual and packaged tourists in Taiwan. Asia Pacific Journal of Tourism Research, 18(6), 573-597. doi: $10.1080 / 10941665.2012 .695281$

Sun, Y.-H. C. (2008). Health concern, food choice motives, and attitudes toward healthy eating: The mediating role of food choice motives. Appetite, 51(1), 4249. doi: http://dx.doi.org/10.1016/j.appet.2007.11.004

Taiwan Department of Household Registration Affairs. (2014, January 22). Population by single year of age. Retrieved August 1, 2014, from http://sowf.moi.gov. tw/stat/year/list.htm

Taiwan Tourism Bureau. (2010). Visitor arrivals by residence 2000-2010. Retrieved 15 June, 2012, from http://admin.taiwan.net.tw/statistics/year_en.aspx?no=15 
Thorsen, L. E. (1991). Norwegian farm women and the cultural meaning of food. Journal of Rural Studies, 7(1-2), 63-66. doi: http://dx.doi.org/10.1016/07430167(91)90041-P

Tomkins, R. (1999, Dec 28). Step forward generation Y: Advertisers are adopting alternative tactics to try to appeal to today's teenagers, writes Richard Tomkins, Financial Times, p. 11.

Wang, C.-H., \& Shen, M.-Y. (2010). Strategies of representation for Southern East Asia foods: Exoticism, multiculturalism, and self-othering identification. Taiwan Journal of Southeast Asian Studies, 7(1), 151-192.

Warde, A., \& Martens, L. (2000). Eating out: Social differentiation, consumption and pleasure. Cambridge: Cambridge University Press.

Warden, C. A., \& Chen, J. F. (2009). When hot and noisy is good: Chinese values of renao and consumption metaphors. Journal of Marketing and Logistics, 21(2), 216-231. doi: 10.1108/13555850910950040

Wong, O. L. (2010). Meaning of food in childhood obesity: An exploratory study in a Chinese family context. Social Work in Health Care, 49(4), 362-377. doi: $10.1080 / 00981380903212149$

Wu, D. Y. H., \& Cheung, S. C. H. (Eds.). (2004). The globalization of Chinese food. New York: Routledge Curzon.

Wu, D. Y. H., \& Tan, C.-B. (2001). Changing Chinese foodways in Asia. Hong Kong: Chinese University.

Wu, S., \& Barker, J. C. (2008). Hot tea and juk: The institutional meaning of food for Chinese elders in an American nursing home. J Gerontol Nurs, 34(11), 46-54.

Yang, C. L., Khoo-Lattimore, C., \& Lai, M. Y. (2013). Eat to live or live to eat? Mapping food and eating perception of Malaysian Chinese. Journal of 
Hospitality Marketing \& Management, 23(6), 579-600. doi: $10.1080 / 19368623.2013 .813887$

Zaltman, G. (1997). Rethinking market research: Putting people back in. Journal of Marketing Research, 34(4), 424-437.

Zaltman, G., \& Coulter, R. H. (1995). Seeing the voice of the customer: Metaphorbased advertising research. Journal of Advertising Research, 35(4), 34-51.

Zanoli, R., \& Naspetti, S. (2002). Consumer motivations in the purchase of organic food. A means-end aprroach. British Food Journal, 104(8), 643-653. doi: $10.1108 / 00070700210425930$ 


\section{Table}

Table 1. Respondents’ Profile

\begin{tabular}{cccc}
\hline Respondent & Gender & Age & Occupation \\
\hline T1 & Female & 30 & Hotel Administrative Executive \\
T2 & Female & 25 & Senior High School Teacher \\
T3 & Female & 26 & Junior High School Teacher \\
T4 & Male & 25 & Postgraduate Student \\
T5 & Male & 27 & Wedding Photographer \\
T6 & Male & 27 & Tour Guide \\
T7 & Female & 26 & Hostel Warden \\
T8 & Female & 26 & Postgraduate Student \\
T9 & Female & 25 & Manufacturing Sales Executive \\
T10 & Female & 28 & Event Photographer \\
T11 & Female & 28 & Advertisement Designer \\
T12 & Female & 26 & Special Education Teacher \\
\hline
\end{tabular}

\section{Figure Captions}

Figure 1. Broad meaning themes for young Taiwanese food and eating perception.

Figure 2. Example of images related to health.

Figure 3. Example of images related to trying new food.

Figure 4. Example of images related to sharing.

Figure 5. Example of images related to happiness. 